$$
\begin{array}{r|l}
\text { Jurnal Sains Komputer dan Teknologi Informasi } & \text { Page } \\
\text { e-issn: 2655-7460. Volume 2 No. 1, November 2019 } & 24-28
\end{array}
$$

\title{
Efektifitas Penggunaan Media Pembelajaran Interaktif Budaya Kalimantan Tengah Bagi Peserta Didik di Sekolah Dasar
}

\author{
Norhayati $^{1}$, Susi Hendartie ${ }^{2}$ \\ Program Studi Sistem Informasi, Sekolah Tinggi Manajemen Informatika dan Komputer \\ (STMIK) Palangkaraya \\ Telp: 0536-3225515, 0536-3224593, e-mail: inoynorhayati@gmail.com ${ }^{1}$, sesyalang@gmail.com²
}

\begin{abstract}
ABSTRAK
Penggunaan media pembelajaran interaktif untuk mendukung kegiatan belajar mengajar telah marak dilakukan oleh para praktisi dibidang pendidikan. Hal ini juga terjadi pada sekolah-sekolah yang ada di provinsi Kalimantan Tengah. Media pembelajaran interaktif dipandang mampu untuk menarik dan meningkatkan minat peserta didik untuk mempelajari bidang mata pelajaran tertentu, tidak terkecuali pada mata pelajaran seni dan budaya. Ragam budaya yang ada di provinsi Kalimantan Tengah menjadi hal yang menarik untuk digunakan sebagai bahan media pembelajaran, baik dari segi audio maupun visual. Untuk mempermudah para peserta didik dalam mengenal dan memahami ragam budaya yang ada maka sebelumnya telah dibuat aplikasi media pembelajaran interaktif. Berkaitan dengan telah adanya media pembelajaran tersebut, maka penulis tertarik untuk meneliti lebih lanjut keefektifan penggunaan media tersebut pada kegiatan belajar dan mengajar. Dalam menguji hal tersebut, maka peserta belajar dibagi menjadi dua kelompok, dimana kelompok ini dibagi berdasarkan kelasnya masing-masing, kelas A dan kelas B. Kelas A diajarkan dengan menggunakan media pembelajaran konvensioal, teks dan gambar, sedangkan kelas B diajarkan menggunakan media pembelajaran interaktif, yang memiliki gambar bergerak dan suara.

Hasil penelitian membuktikan bahwa para peserta didik yang diajarkan menggunakan media pembelajaran interaktif memperoleh nilai evaluasi belajar yang lebih tinggi dibandingkan perseta didik yang diajarkan secara konvensional. Selain itu minat belajar yang lebih tinggi juga ditunjukkan oleh para peserta didik yang mendapat perlakukan berbeda. Berdasarkan hasil tersebut maka dapat ditarik keimpulan bahwa efektifitas penggunaan media pembelajaran interaktif terbukti memberi pengaruh positif terhadap minat dan hasil belajar peserta didik dalam memahami budaya Kalimantan Tengah.
\end{abstract}

\section{Kata kunci : Media belajar interaktif, efektifitas, minat belajar, budaya Kalimantan Tengah.}

\section{PENDAHULUAN}

Penggunaan media belajar yang interaktif dalam kegiatan belajar dan mengajar telah sangat marak dilakukan oleh para tenaga pendidik pada masa kini. Media belajar interaktif yang digunakan ada yang berupa aplikasi jadi atau memaksimalkan penggunaan aplikasi Microsoft Power Point untuk membuat media tersebut. Hal ini merupakan bukti nyata bahwa kolaborasi tenaga pendidik dan tenaga bidang teknologi telah memberikan dampak nyata bagian kegiatan belajar dan mengajar.

Kalimantan Tengah memiliki corak kebudayaan yang beragam. Untuk menjaga dan melestarikan warisan budaya tersebut, yang mana merupakan ciri khas warga Kalimantan Tengah, maka dirasa sangat penting untuk mengenalkan budaya Kalimantan Tengah kepada anak-anak, khususnya warga Kalimantan Tengah. Dalam kurikulum sekolah, pelajaran tentang budaya Kalimantan Tengah tertuang dalam pelajaran muatan lokal.

Pada sistem belajar mengajar konvensional, materi tentang budaya Kalimantan Tengah diajarkan dengan menggunakan media teks cerita dan gambar. Media ini masih cukup efektif untuk menambah pengetahuan para peserta didik akan tetapi masih dirasa kurang untuk menarik minat peserta didik agar lebih semangat belajar pelajaran Muatan Lokal tersebut. Untuk menjawab problematika tersebut, maka dibuatlah suatu media dengan memanfaatkan aplikasi Microsoft Power Point.

Penelitian ini merupakan pengembangan dari penelitian sebelumnya yang telah menghasilkan aplikasi media pembelajaran interaktif tentang budaya Kalimantan Tengah. Tujuan dari dilakukannya penelitian ini adalah untuk membuktikan keefektifan penggunaan media belajar interaktif dalam mengenalkan budaya Kalimantan Tengah bagi peserta didik dibangku sekolah dasar serta dampaknya terhadap minat dan hasil belajar para peserta didik.

\section{MEDIA PEMBELAJARAN INTERAKTIF}

Media pembelajaran interaktif adalah segala sesuatu yang menyangkut software dan hardware yang dapat digunakan sebagai perantara untuk menyampaikan isi materi ajar dari sumber belajar 
ke pembelajar dengan metode pembelajaran yang dapat memberikan respon balik terhadap pengguna dari apa yang telah diinputkan kepada media tersebut.

Kualitas media pembelajaran dapat dinilai melalui ukuran-ukuran dan metode-metode tertentu, serta melalui pengujian-pengujian software. Menurut Walker dan Hess (1984:206) yang dikutip oleh Azhar Arsyad (20011:175-176), kriteria kualitas media pembelajaran interaktif dapat dinilai berdasarkan kualitas materi dan tujuan, kualitas pembelajaran, dan kualitas Teknik.

Menurut Sudjana dan Rivai (dalam Arsyad, 2011:24-25), beberapa manfaat media pembelajaran antara lain:

a. Pembelajaran akan lebih menarik perhatian peserta didik sehingga dapat menumbuhkan motivasi belajar.

b. Bahan pembelajaran akan lebih jelas sehingga dapat lebih dipahami oleh peserta didik.

c. Metode mengajar akan lebih bervariasi dan tidak membosankan.

d. Peserta didik dapat lebih banyak melakukan kegiatan belajar.

\section{RAGAM BUDAYA KALIAMNTAN TENGAH}

Kalimantan Tengah memiliki budaya yang sangat beragam, diantaranya:

a. Pakaian adat/pakaian pengantin

1) Busana Pengantin Dayak

Busana pengantin pria Dayak Kalimantan Tengah memakai celana panjang sampai lutut, selempit perak atau tali pinggang dan tutup kepala. Perhiasan yang dipakai adalah inuk atau kalung panjang, cekoang atau kalung pendek dan kalung yang terbuat dari gigi binatang. Pengantin wanita memakai kain berupa rok pendek, rompi, ikat kepala dengan hiasan bulu enggang gading, kalung dan subang.

2) Busana Pengantin Kotawaringin Busana Adat Banjar-Kotawaringin keraton Kesultanan Kotawaringin, salah satu sukubangsa di Kalimantan Tengah. Busana pengantin Kotawaringin mirip dengan Busana Pengantin Banjar, namun terdapat beberapa perbedaan.

3) Alat perang

Alat perang yang menjadi ciri khas Kalimantan Tengah yang terkenal adalah mandau, sumpit, lunju, dohong dan talawang

4) Alat musik tradisional
Alat musik tradisional yang ada di Kalimantan Tengah adalah: garantung, japen, katambung, salung, saron, serupai/tote, suling bahalang dan suling balawung.

5) Tari-tarian tradisional

Jenis tari-tarian yang ada di Kalimantan Tengah sangat beragam, diantaranya adalah sebagai berikut:

1) Tari Hugo dan Huda

2) Tari Putri Malawen

3) Tari Tuntung Tulus dari Barito Timur

4) Tari Giring-giring

5) Manasai

6) Tari Balian Bawo

7) Tari Balian Dadas

\section{MINAT DAN HASIL BELAJAR}

a. Minat belajar

Menurut Ahmadi (2009: 148) "Minat adalah sikap jiwa orang seorang termasuk ketiga fungsi jiwanya (kognisi, konasi, dan emosi), yang tertuju pada sesuatu dan dalam hubungan itu unsur perasaan yang kuat".

Menurut Slameto (2003:180), "minat adalah kecenderungan yang tetap untuk memperhatikan dan mengenang beberapa kegiatan". Sedangkan menurut Djaali (2008: 121) "minat adalah rasa lebih suka dan rasa ketertarikan pada suatu hal atau aktivitas, tanpa ada yang menyuruh". Sedangkan menurut Crow\&crow (dalam Djaali, 2008: 121) mengatakan bahwa "minat berhubungan dengan gaya gerak yang mendorong seseorang untuk menghadapi atau berurusan dengan orang, benda, kegiatan, pengalaman yang dirangsang oleh kegiatan itu sendiri".

Dari beberapa pendapat para ahli diatas dapat disimpulkan bahwa pengertian minat adalah rasa ketertarikan, perhatian, keinginan lebih yang dimiliki seseorang terhadap suatu hal, tanpa ada dorongan.

b. Hasil belajar

Bukti bahwa seseorang telah belajar ialah terjadinya perubahan tingkah laku pada orang tersebut, misalnya dari tidak tahu menjadi tahu, dan dari tidak mengerti menjadi mengerti (Hamalik, 2008: 30).

Menurut Dimyati dan Mudjiono (1999), hasil belajar merupakan hal yang dapat dipandang dari dua sisi yaitu sisi 


$$
\begin{array}{r|l}
\text { Jurnal Sains Komputer dan Teknologi Informasi } & \text { Page } \\
\text { e-issn: 2655-7460. Volume } 2 \text { No.1, November 2019 } & 24-28
\end{array}
$$

peserta didik dan dari sisi guru. Dari sisi peserta didik, hasil belajar merupakan tingkat perkembangan mental yang lebih baik bila dibandingkan pada saat sebelum belajar.

Kingsley (Nana Sudjana, 2005: 85) membagi 3 macam hasil belajar: 1) Keterampilan dan kebiasaan; 2) Pengetahuan dan pengertian; dan 3) Sikap dan cita-cita. Pendapat dari Kingsley ini menunjukkan hasil perubahan dari semua proses belajar. Hasil belajar ini akan melekat terus pada diri peserta didik karena sudah menjadi bagian dalam kehidupan peserta didik tersebut.

Berdasarkan pengertian di atas maka dapat disintesiskan bahwa hasil belajar adalah suatu penilaian akhir dari proses dan pengenalan yang telah dilakukan berulang-ulang. Serta akan tersimpan dalam jangka waktu lama atau bahkan tidak akan hilang selama-lamanya karena hasil belajar turut serta dalam membentuk pribadi individu yang selalu ingin mencapai hasil yang lebih baik lagi sehingga akan mengubah cara berpikir serta menghasilkan perilaku kerja yang lebih baik.

\section{METODE PENELITIAN}

Penelitian ini menggunakan metode analisa deskriptif dengan pendekatan kuantitatif. Sebagaimana yang dikemukakan oleh Sudjana dan Ibrahim (1989:64) bahwa: "penelitian deskriptif merupakan penelitian yang berusaha untuk mendeskripsikan suatu gejala, peristiwa dan kejadian yang terjadi pada saat sekarang dimana peneliti berusaha memotret dan kejadian yang menjadi pusat perhatian untuk kemudian digambarkan sebagai adanya".

Ali (1982:120) menjelaskan bahwa "metode penelitian deskriptif digunakan untuk memecahkan sekaligus menjawab permasalahan yang terjadi pada masa sekarang".Metode yang digunakan dalam penelitian ini adalah metode deskriptif kuantitatif.

Sedangkan yang dimaksud dengan pendekatan kuantitatif adalah pendekatan yang digunakan dalam penelitian dengan cara mengukur indikator-indikator variabel penelitian sehingga diperoleh gambaran dianara variabel-variabel tersebut. Tujuan dari pendekatan kuantitatif menurut Surakhmad (1988:139) adalah: "untuk mengukur dimensi yang hendak diteliti"

Adapun tujuan penelitian deskriptif dengan pendekatan kuantitatif ini adalah untuk menjelaskan suatu situati yang hendak diteliti didukung dengan studi pustaka dan data-data yang valid.

\section{HASIL DAN PEMBAHASAN}

Sampel yang digunakan dalam peneltian ini adalah peserta didik kelas $\mathrm{V}$ pada SDN-5 Langkai Palangkaraya. Sampel tersebut dibagi menjadi dua kelas, yakni kelas A dan kelas B.

Peserta didik pada kelas A diajarkan dengan menggunakan media pembelajaran konvensioal, teks dan gambar, sedangkan kelas B diajarkan menggunakan media pembelajaran interaktif, yang memiliki gambar bergerak dan suara.

6.1 Data Pretest (O1)

Data Pretest ini terdiri dari 10 soal, diberikan kepada peserta didik untuk menguji tingkat pengetahuan yang telah dimiliki, sehingga didapat hasil sebagai berikut :

\begin{tabular}{ccccc}
\multicolumn{4}{c}{ Tabel 1.1 Data Pretest $\left(\mathrm{O}_{1}\right)$} \\
\hline No & $\begin{array}{c}\text { Kode } \\
\text { sampel } \\
\text { kelas A }\end{array}$ & $\begin{array}{c}\text { Skor } \\
\text { kelas A }\end{array}$ & $\begin{array}{c}\text { Kode } \\
\text { sampel } \\
\text { kelas B }\end{array}$ & $\begin{array}{c}\text { Skor } \\
\text { kelas B }\end{array}$ \\
\hline 1. & A-1 & 70 & B-1 & 60 \\
2. & A-2 & 50 & B-2 & 80 \\
3. & A-3 & 70 & B-3 & 40 \\
4. & A-4 & 40 & B-4 & 70 \\
5. & A-5 & 60 & B-5 & 60 \\
6. & A-6 & 80 & B-6 & 50 \\
7. & A-7 & 40 & B-7 & 70 \\
8. & A-8 & 70 & B-8 & 50 \\
9. & A-9 & 60 & B-9 & 70 \\
10. & A-10 & 50 & B-10 & 40 \\
11. & A-11 & 70 & B-11 & 60 \\
12. & A-12 & 50 & B-12 & 80 \\
13. & A-13 & 70 & B-13 & 40 \\
14. & A-14 & 40 & B-14 & 70 \\
15. & A-15 & 60 & B-15 & 60 \\
16. & A-16 & 80 & B-16 & 50 \\
17. & A-17 & 40 & B-17 & 40 \\
18. & A-18 & 70 & B-18 & 70 \\
19. & A-19 & 60 & B-19 & 60 \\
20. & A-20 & 50 & B-20 & 50 \\
21. & A-21 & 40 & B-21 & 70 \\
22. & A-22 & 70 & B-22 & 50 \\
23. & A-23 & 60 & B-23 & 70 \\
24. & A-24 & 50 & B-24 & 40 \\
\hline & & & & \\
\hline
\end{tabular}

6.2 Data Post-test (O2)

Data Posttest merupakan dihasilkan melalui treatment atau perlakuan khusus terhadap sampel, sehingga didapat hasil sebagai berikut :

Tabel 1.2 Data Posttest $\left(\mathrm{O}_{2}\right)$

\begin{tabular}{lllll}
\hline No & Kode & Skor & Kode & Skor \\
\hline
\end{tabular}




$$
\begin{aligned}
& \text { Norhayatí \& Susi Hendartie. Efektifitas Penggunaan Media Pembelajaran Interaktif Budaya } \\
& \text { Kalimantan Tengah Bagi Peserta Didik di Sekolah Dasar }
\end{aligned}
$$

\begin{tabular}{ccccc}
\hline & $\begin{array}{c}\text { sampel } \\
\text { kelas A }\end{array}$ & kelas A & $\begin{array}{c}\text { sampel } \\
\text { kelas B }\end{array}$ & kelas B \\
\hline 1. & A-1 & 70 & B-1 & 80 \\
2. & A-2 & 60 & B-2 & 100 \\
3. & A-3 & 60 & B-3 & 80 \\
4. & A-4 & 60 & B-4 & 80 \\
5. & A-5 & 70 & B-5 & 70 \\
6. & A-6 & 70 & B-6 & 100 \\
7. & A-7 & 50 & B-7 & 70 \\
8. & A-8 & 50 & B-8 & 90 \\
9. & A-9 & 50 & B-9 & 80 \\
10. & A-10 & 60 & B-10 & 70 \\
11. & A-11 & 60 & B-11 & 80 \\
12. & A-12 & 80 & B-12 & 100 \\
13. & A-13 & 70 & B-13 & 80 \\
14. & A-14 & 60 & B-14 & 80 \\
15. & A-15 & 60 & B-15 & 70 \\
16. & A-16 & 60 & B-16 & 100 \\
17. & A-17 & 70 & B-17 & 70 \\
18. & A-18 & 70 & B-18 & 90 \\
19. & A-19 & 80 & B-19 & 80 \\
20. & A-20 & 80 & B-20 & 70 \\
21. & A-21 & 60 & B-21 & 100 \\
22. & A-22 & 70 & B-22 & 70 \\
23. & A-23 & 70 & B-23 & 90 \\
24. & A-24 & 80 & B-24 & 80 \\
\hline & & & & \\
\hline
\end{tabular}

Dari hasil Pretest dan Postest di atas dapat ditarik kesimpulan bahwa seluruh Peserta Didik mengalami peningkatan nilai setelah dilakukan pengembangan pembelajaran interaktif budaya menggunakan Ms. PowerPoint. Dengan menghitung skor pretest pada sampel yang diberikan maka didapatlah nilai rata-rata yaitu 60 , sedangkan untuk nilai pada skor posttest yaitu 82 .

Tim penulis juga melakukan observasi selama kegiatan belajar mengajar berlangsung. Kegiatan observasi ini dilakukan sebanyak 3 (tiga) kali. Observasi pertama dilakukan pada saat penjelasan materi, sebelum pre-test dilakukan. Observasi kedua dikalukan pada saat pemberian materi menggunakan media pembelajaran interaktif. Observersi kedua dilaksanakan setelah post-test dilakukan. Adapun unsur-unsur yang diamati selama obervasi adalah sebagai berikut:

\begin{tabular}{|c|c|c|c|c|c|}
\hline No & Uraian & $\begin{array}{c}\begin{array}{c}\text { Sangat } \\
\text { baik }\end{array} \\
\text { bet }\end{array}$ & Baik & $\begin{array}{c}\begin{array}{c}\text { Biasa } \\
\text { saja }\end{array} \\
\end{array}$ & $\begin{array}{c}\text { Tidak } \\
\text { baik }\end{array}$ \\
\hline 1. & $\begin{array}{l}\text { Respon peserta didik } \\
\text { terhadap tampilan } \\
\text { media belajar interaktif }\end{array}$ & & & & \\
\hline 2. & $\begin{array}{l}\text { Respon peserta didik } \\
\text { terhadap bagian gambar } \\
\text { bergerak/aniamsi }\end{array}$ & & & & \\
\hline 3. & $\begin{array}{l}\text { Respon peserta didik } \\
\text { terhadap audio cerita }\end{array}$ & & & & \\
\hline 4. & $\begin{array}{l}\text { Respon peserta didik } \\
\text { dalam mengerjakan }\end{array}$ & & & & \\
\hline
\end{tabular}

Tabel 1.3 Lembar Observasi kuis interaktif

Berikut ini merupakan contoh dari materi interaktif yang digunakan dalam kegiatan belajar mengajar.
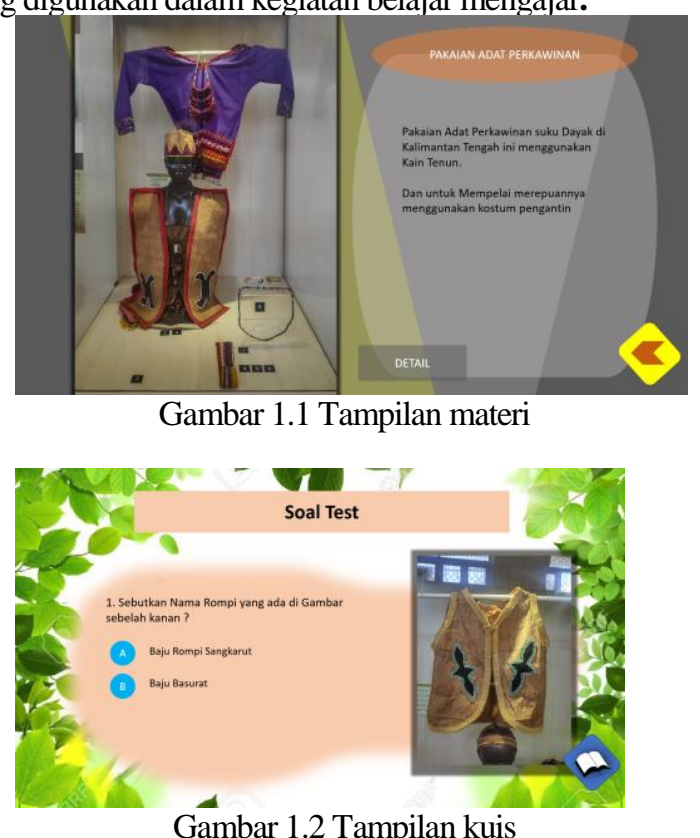

\section{KESIMPULAN DAN SARAN}

7.1. Berdasarkan dari hasil penelitian dan pembahasan sebelumnya maka diperoleh kesimpulan, yaitu sebagai berikut :

1. Dengan menggunakan media belajar interaktif power point, peserta didik lebih fokus dalam pembelajaran serta adanya tanya jawab yang dihasilkan dari metode belajar yang memanfaatkan media power point.

2. Berdasarkan penelitian yang telah dilakukan, didapat Dari hasil Pretest dan Postest di atas dapat ditarik kesimpulan bahwa seluruh Peserta Didik mengalami peningkatan nilai setelah dilakukan pengembangan pembelajaran interaktif budaya menggunakan Ms. PowerPoint. Dengan menghitung skor pretest pada sampel yang diberikan maka didapatlah nilai rata-rata yaitu 60 poin, sedangkan untuk nilai pada skor posttest yaitu 82 poin.

3. Pengimplementasian teknologi dalam pembelajaran dapat meningkatkan minat, dan ketertarikan peserta didik didalam belajar sehingga baik peserta didik maupun guru mendapatkan dampak positif dalam penerapan ilmu pembelajaran. 


$$
\begin{array}{r|l}
\text { Jurnal Sains Komputer dan Teknologi Informasi } & \text { Page } \\
\text { e-issn: 2655-7460. Volume } 2 \text { No.1, November 2019 } & 24-28
\end{array}
$$

7.2. Tim peneliti menyarankan kepada para pendidik dan kepada para ahli dalam bidang teknologi agar dapat terus selalu berkolaborasi untuk menciptakan inovasi dalam kegiatan belajar dan mengajar. Hal ini sangat penting guna memaksimalkan hasil dari proses kegiatan belajar dari peserta didik serta menciptakan suasana belajar yang menyenangkan dan memberikan pengalaman baru dalam memanfaatkan sisi positif dari teknologi yang akan selalu terus berkembang.

\section{UCAPAN TERIMA KASIH}

Terima kasih yang sebesar-besarnya tim penulis ucapkan kepada:

1. Pihak manajemen SDN-5 Langkai Palangkaraya

2. Pihak manajemen STMIK Palangkaraya

3. Yunus Ramadhan selaku pengembang aplikasi media belajar interaktif

4. Serta seluruh pihak yang telah mendukung penelitian ini sehingga bisa terselesaikan dengan baik.

\section{DAFTAR PUSTAKA}

Ahmadi, Abu. 2009. Psikologi Sosial. Jakarta: Rineka Cipta.

Ali, Muhammad. 1982. Penelitian Pendidikan Prosedur dan Strategi. Angkasa. Bandung. 215 Halaman

Dimyati Dan Mudjiono. 1999. Belajar Dan Pembelajaran, Jakarta: Rineka Cipta.

Djaali. 2008. Psikologi Pendidikan. Jakarta: Bumi Aksara

Hamalik. 2008. Proses Belajar Mengajar. Bandung : Bumi Aksara.

https://disbudpar.kalteng.go.id/

Norhayati dan Rosmiati. 2019. Implementasi Media Pembelajaran Berbasis Multimedia Untuk Meningkatkan Minat dan Motivasi Belajar Bahasa Inggris pada Anak Di Desa Petuk Ketimpun Provinsi Kalimantan Tengah. Jurnal Sains Komputer dan Teknologi Informasi. Vol 1 Issue 2 e-ISSN 2655-7460. https://doi.org/10.33084/jsakti.v1i2.872.

Qamaruzzaman, M. H., Prasetya, T., Islamova, S, A., 2018. Sistem Informasi Berbasis Mobile Benda-Benda Tradisional Pada Museum Balanga Palangkaraya. Jurnal Sains Komputer dan Teknologi Informasi. Vol 1 Issue 1 e-ISSN 2655-7460. https://doi.org/10.33084/jsakti.v1i1.455.

Sam'ani. Annisa, S., Heri., 2018. Rancang Bangun Aplikasi Pengawasan Dan Pengendalian Komputer Laboratorium Multimedia STMIK
Palangkaraya. Jurnal Sains Komputer dan Teknologi Informasi. Vol 1 Issue 1 e-ISSN 2655-7460.

https://doi.org/10.33084/jsakti.v1i1.548.

Slameto. 2013. Belajar \& Faktor-Faktor Yang Mempengaruhi. Jakarta: Pt Rineka Cipta.

Sudjana, Nana, dan Ibrahim, 1989, Penelitian Kualitatif dan Kuantitatif, Bandung: Sinar Baru

Sudjana, Nana. 2005. Dasar-dasar Proses\Belajar Mengajar. Bandung. Sinar Baru Algensindo.

Sudjana, Nana. 2010. Cara Belajar Siswa Aktif dalam Proses Belajar Mengajar. Bandung. Sinar Baru Algensindo.

Sudjana. 2001. Metode \& Teknik Pembelajaran Partisipatif. Bandung : Falah Production.

Sugiyono. 2011. Metode Penelitian Kuantitatif, Kualitatif Dan R \& D. Bandung: Alfabeta 